\title{
Slow Growing Palatal Swelling- A Diagnostic Dilemma A Case Report and IndepthReview of Contemporary Literature
}

\author{
Shrivastava K, Bailoor DN, Naidu G, Raghuvanshi V, Handa H
}

\begin{abstract}
The adenoid cystic carcinoma is a relatively rare epithelial tumor more than half of these occur in the parotid and submandibular glands. The most common intraoral site is the palate. Its peak incidence occurs predominantly among women, between the 5th and 6th decades of life. The clinical and pathological findings typical of this tumor include slow growth, perineural invasion, potential local recurrence and distant metastasis. Histopathologically it is composed of basaloid cells with primarily myoepithelial/basal cell differentiation. It presents three patterns, cribriform, tubular and solid; the solid type is related to a poor prognosis contrary to the cribriform type, which has a better prognosis. We presented herein the case of a 26 year old male patient who presented a palatal lesion with an indepth review of literature.

Keywords: Carcinoma, Adenoid cystic, Palate
\end{abstract}

\section{Introduction}

Adenoid cystic carcinoma is a rare epithelial tumor affecting the salivary glands and was first described in $1856^{1}$ and at the time was referred to as cylindroma due to its unique histologic appearance.In 1928 it was renamed adenoid cystic carcinoma (ACC) and since then has been the generally accepted term for this neoplasm ${ }^{2}$.It comprises less than $1 \%$ of all malignancies of the head and neck and is the fifth most common malignancy of salivary gland origin, representing $10 \%$ of salivary gland malignancies ${ }^{3}$.As per ICD-O code 8200/3. The parotid and submandibular glands are the two most common sites for ACC accounting for 55\% of the cases. The long natural history of this tumor, its propensity for perineural invasion, and its tendency for local recurrence are well $\mathrm{known}^{3}$.Its peak incidence occurs predominantly among women, between the 5th and 6th decades of life ${ }^{4}$.We present a case of ACC of the hard palate minor salivary glands, and a literature review on its clinical, histopathological and management aspects.

\section{Differential Diagnosis of Palatal Swelling}

The clinical differential diagnosis for such a slow-growing, soft, fluctuant midline swelling of the palate can be lesions like -

Pleomorphic Adenoma ${ }^{5}$ is a benign neoplasm which is commonly encountered in the parotid gland. At times they can also develop in minor salivary glands of the palate and lips. The majority of minor salivary gland tumors are malignant. It may occur at any age, but mainly they affect patients in the $4^{\text {th }}, 5^{\text {th }}$ and $6^{\text {th }}$ decades. Forty percent of them are male, $60 \%$ female. They are painless, well-delineated and covered with normal mucous membrane. Sometimes mucosal ulcerations are observed. Major gland tumors are usually encapsulated, as opposed to minor gland tumors. When originating in the minor salivary glands ${ }^{6}$, in most cases it occurs on the soft and hard palate due to the highest concentration of salivary glands there and is typically a firm or rubbery submucosal mass without ulceration or surrounding ulceration.

Monomorphic Adenoma ${ }^{78}$ this tumor of the minor salivary glands represents $15 \%$ of all salivary gland tumors.It is an uncommon histological type that usually is located in the parotid gland, minor salivary glands of the upper lip and less frequently, palate.

Ductal Papilloma ${ }^{9}$ is a group of relatively rare, benign, papillary salivary gland tumours known as inverted ductal papilloma or intraductal papilloma. They represent adenomas with unique papillary features with a common relationship to the excretory salivary duct system, a nonaggressive biologic behaviour, and a predilection for the minor salivary glands. They tend to occur in the middle-aged and elderly typically presents as a painless nodular submucosal swelling with a dilated punctum surfacing the swelling.

Low grade mucoepidermoid tumor ${ }^{10}$ is the most common malignant tumor of the minor salivary glands (12$29 \%$ ). When MEC arises in minor salivary glands it can be located on the palate, in the retromolar area, the floor of the mouth, the buccal mucosa, the lips and the tongue. The greatest incidence occurs between the $3^{\text {rd }}$ and $6^{\text {th }}$ decade of life. 
Slow growing palatal swelling-A diagnostic Dilemma A Case Report and Indepth review of...

Mucous adenocarcinoma ${ }^{7}$ is a low grade rare malignant neoplasm. The incidence is unknown but submandibular gland is the most common site a few cases with minor salivary gland have also been reported. The tumor may be associated with dull pain and tenderness.

Papillary cystadenomalymphomatosum or Warthins tumor ${ }^{711}$ is the $2^{\text {nd }}$ most common tumor of the salivary gland occurring exclusively in the parotid gland .The intra-oral accessory salivary gland are rarely affected. A strong association between development of this tumor and smoking has been documented. It occurs more commonly in men in sixth and seventh decade of life. It is non tender and firm on palpation.

Nasopharyngeal Carcinoma (NPC) ${ }^{4}$ is a tumor arising from the epithelial cells that cover the surface and line the nasopharynx. It is thought to be the result of both genetic susceptibility and environmental factors such as carcinogens and infection with Epstein-Barr virus (EBV), consumption of salted fish containing nitrosamines and heavy alcohol intake.NPC has a bimodal age distribution being observed in late childhood, and also in people aged 50-60 years. Symptoms include trismus, pain, otitis media; paresis of soft palate, cranial nerve palsies, and headache .Larger growths may produce nasal obstruction or bleeding

Carcinoma of Maxillary Antrum ${ }^{12}$ is an exceedingly dangerous disease although the actual incidence with respect to intra-oral carcinoma is less. Available studies indicate that $\mathrm{Ca}$ of Antrum is more common in elderly men, occasional it can occur in young individuals. Symptoms include unilateral nasal stuffiness/discharge, loosening of teeth, inability to tolerate dentures etc.

\section{Case Report}

A 26 year old male patient came with the chief complaint of swelling in the palatal region since 4 years. The swelling had been gradually increasing and since one month was associated with pain and burning sensation. Patient's general physical examination did not reveal any abnormality and the vitals were within the normal range. On extra-oral examination no abnormality was detected and no lymphnode involvement was noted. On intra-oral examination a single, midline, diffuse swelling approximately $4 \times 3 \mathrm{cmextending} 0.5 \mathrm{~cm}$ across the midline on the right side and $3 \mathrm{~cm}$ on the left side and from post rugae area to the anterior vibrating line was seen on the palate(Fig 1.).The swelling was tender, soft and fluctuant.

As a part of chairside investigation aspiration was performed from two different areas of the swelling(Fig 2) and a few drops of blood aspirate was obtained(Fig 3) and cytopathological examination revealeddense agglomerates of RBC's along with diffuse isolated chronic inflammatory cells. Very few epithelial cells containing ovoid nuclei were seen in a fibrillar background suggestive of glandular epithelium (Fig 5).Also routine radiographic examination consisted of Orthopantomogram(Fig 5) and Paranasal Sinus (Fig 6) which did not reveal anything significant. However MRI (Fig 7)revealeda well definedheterogenously enhancing mass on soft palate measuring $3.8 \mathrm{~cm} \times 4.5 \mathrm{~cm} \times 4 \mathrm{~cm}$ indicating the possibility was minor salivary gland tumor.

Based on patient's history, clinical and radiographic examination a provisional diagnosis of a neoplasm of minor salivary gland of the palate was given. The laboratory investigations were undertaken, which rendered normal results. Anendoscopic nasal incisional biopsy was taken and histopathological analysis revealed cribriform glands lined by hyperchromatic cells, focal areas showed basement membrane material in the centre surrounded by small round hyperchromatic cells which finally confirmed the diagnosis of Adenoid Cystic Carcinoma.

\section{Discussion}

In 1859, Billroth used the term "cylindroma" to describe the histological standard of four salivary gland tumors ${ }^{1}$. However, use of the term cylindroma should be avoided because the same term is used for a skin adnexal tumor that has a markedly different clinical presentation and prognosis. ACC is an uncommon form of malignant neoplasm that arises most commonly in the major and minor salivary glands of the head and neck. ACC make up about $6 \%$ of all salivary gland tumors.

\section{Clinical Features}

ACC affects women predominantly in and usually occurs in the $5^{\text {th }}$ and 6 th decade of life and is rare in people younger than age $20^{3,4}$. Although palate is the most commonly involved intraoral site.Isacsson and Shear ${ }^{13}$ reported occurrences of ACC in the palate, floor of the mouth, tongue and gingiva in decreasing order. It usually presents as a slowly growing firm unilobular mass in the gland. Pain is a common and important finding occurring in the early course of the disease, before there is a noticeable swelling. Parotid tumors may cause facial nerve paralysis in a small number of patients. Unfortunately, the tumor's slow growth may delay diagnosis for several years, allowing perineural invasion to be advanced at the time of surgical management ${ }^{14}$. The clinical differential diagnosis for such palatal swelling may include various salivary gland neoplasms, carcinoma of maxillary antrum, nasopharyngeal carcinoma etc. 


\section{Histopathological Features}

Microscopically ACC is composed of a mixture of myoepithelial cells andductal cells. Histopathologically,ACC presents three patterns, cribriform, tubular and solid. Thecribriform (glandular) pattern is the most classic and best recognizedappearance, characterized by islands of basaloidepithelialcells that contain multiple cylindrical, cyst-like spaces resemblingSwiss chees $\mathrm{e}^{15}$. These spaces often contain a mildly basophilic mucoid material, a hyalinizedeosinophilic product, or a combined mucoidhyalinized appearance ${ }^{7}$. The tumor cells are small and cuboidal exhibiting deeply basophilic nuclei and little cytoplasm ${ }^{15}$.Szantoet al ${ }^{6}$ have defined a three tier grading system on the basis of the histomorphologic pattern and percentage of the solid component. Grade 1 ACCs are well differentiated and composed of tubular and cribriform patterns without solid components; Grade 2 ACCs are characterized by a pure cribriform pattern or mixed with less than $30 \%$ of solid areas; and Grade 3 ACCs are tumors with marked predominance of the solid pattern.

\section{Management}

Possible treatments of ACC include four different modalities; surgery, radiotherapy, chemotherapy and combined therapy. Surgical excision with wide margins is the treatment of choice. However, there is still controversy regarding the adjuvant treatment of this tumor. Postoperative radiotherapy is also indicated for cases of tumor location close to the base of the cranium with the presence of neck lymph node metastasis and perineural invasion, the solid histological subtype, and in the case of recurrent tumors. Various authors suggested that only surgical removal or radiotherapy in isolation may fail to eliminate the possibility of recidivation in surgical margins, as well as the occurrence of metastasis in cervicallymph nodes, lungs, bones and brain. On the other hand, chemotherapy use for ACC is controversial ${ }^{1}$.

\section{Conclusion}

Adenoid cystic carcinomais a rare and a challenging pathology due to the many unknown factors that are still debated today in regard to its evolution and treatment. The great tendency of this tumor to recur locally and to develop distant metastasis, even late ones and after having achieved adequate loco regional control requires us to maintain close, lifelong follow-up of these patients. The cure rate of patients with this disease is discouragingly low. The factors affecting prognosis are the site of occurrence and the histologic pattern of the tumor.

\section{References}

[1]. Bilroth T. Die cylindergeschwulst (cylindroma). Untersuchungenuber die Entwicklung der Blutgefasse, nebstBeobachtungenaus der koniglichenchirugischenUniverstats-Klink zu Berlin Berlin. Germany: G Riemer; 1856, 55-69.

[2]. Berdel P, Mylius E. Cylindroma of the salivary gland. ActaOtolaryngolSuppl (Stockh) 1970;263:170. p. 170

[3]. Spiro RH, Huvos AG, Strong EW. Adenoid cystic carcinoma: factors influencing survival. Am J ClinPathol 1979;138:579-83

[4]. Waldron CA, El-Mofty SK, Gnepp DR. Tumors of the intraoral minor salivary glands: a demographic and histologic study of 426 cases. Oral Surg Oral Med Oral Pathol 1988;66:323-33.

[5]. Vellios F, Shafer WG. Tumors of minor salivary glands. SurgGynecolObstet 1959; 108: 450-6

[6]. Mansur Rahnama, UrszulaOrzędała-Koszel, ŁukaszCzupkałło, MichałŁobacz. Pleomorphic adenoma of the palate:a case report and review of the literature. WspolczesnaOnkol 2013; 17 (1): 103-106

[7]. Neville BW, Damm DD, Allen CM, Bouquot JE. Oral and maxillofacial pathology. 3rd ed. St. Louis: Saunders Elsevier; 2009

[8]. Zabaleta M, Mollá FJ, Salazar F, Erdozain I, Sánchez L. Monomorphic adenoma of basal cells in a minor salivary gland. ActaOtorrinolaringol Esp. 1997 Mar;48(2):169-72

[9]. Brannon RB, Sciubba JJ, Giulani M. Ductal papillomas of salivary gland origin: A report of 19 cases and a review of the literature. Oral Surg Oral Med Oral Pathol Oral RadiolEndod. 2001 Jul;92(1):68-77.

[10]. Triantafillidou K, Dimitrakopoulos J, Iordanidis F Koufogiannis D. Mucoepidermoid carcinoma of minor salivary glands:a clinical study of 16 cases and review of the literature. Oral Diseases (2006) 12, 364-370

[11]. Gates GA. Malignant neoplasm of the minor salivary glands. N Engl J Med 1982;306:718-22

[12]. Goepfert H, Luna MA, Lindberg RD, White AK. Malignant salivary gland tumors of the paranasal sinuses and nasal cavity. Arch Otolaryngol 1983;109:662-8

[13]. Isacsson G, Shear M. Intraoral salivary gland tumors: a retrospective study of 201 cases. J Oral Pathol 1983;12:57-62.

[14]. M Shailesh et al. Adenoid cystic carcinoma: A rare clinical entity and literature review.Oral Oncology 47 (2011) 231-236

[15]. Regazi J, Sciubba J. Salivary gland disease. In: Oral pathology. Regazi J, Sciubba J, editors. Philadelphia: W.B. Saunders Co.; 1993. pp. 239-302 